\title{
Robust New Statistical Approaches to the Discimination of Mantle- and Crust-derived Low-Cr garnets using Major and Trace Element Data
}

\author{
Matthew F. Hardman ${ }^{1}$, D. Graham Pearson ${ }^{1}$, Thomas Stachel ${ }^{1}$ and Russell J. Sweeney ${ }^{2}$ \\ ${ }^{1}$ University of Alberta,Edmonton, Canada, mhardman@ualberta.ca, gdpearso@ualberta.ca, \\ tstachel@ualberta.ca \\ ${ }^{2} R J$ Sweeney Consulting, Eastbourne, United Kingdom, russelljsweeney@gmail.com
}

\section{Introduction}

Diamond exploration focuses on geochemical analysis of indicator minerals that are much more abundant than diamond itself. While exploration practices using peridotitic xenocrysts are robust and widely-used, similar methodologies are underdeveloped for eclogitic indicator minerals. Low-Cr garnets from mantle eclogites overlap compositionally with those of many lower-crustal lithologies transported by kimberlite. Misclassification of such crustal garnets may create "false positive" mantle signatures, possibly leading to a misdirection of exploration effort.

\section{Dataset}

We have produced new major and trace element geochemical data for paired garnet and clinopyroxene from 564 kimberlite-hosted, crust- and mantle-derived samples from cratons worldwide. Sample character was determined based on xenolith petrography: crustal samples are plagioclase-bearing and primarily garnet-granulites while mantle samples are a mixture of eclogite and pyroxenite. Garnets contain $<1.00 \mathrm{wt} . \% \mathrm{Cr}_{2} \mathrm{O}_{3}$ in all instances. Trace elements were analyzed by sector-field laser ablation inductively-coupled plasma mass spectrometry (LA-ICP-MS) and include $\mathrm{Sr}, \mathrm{Zr}, \mathrm{Y}, \mathrm{Nb}, \mathrm{Ba}, \mathrm{Hf}$ and the REE (rare earth elements). The combined major and trace element data set allows us to compare error rates between new trace element-based and existing major element-based schemes, and derive new combined major- and trace-element-based schemes.

\section{Background}

The garnet classification scheme of Schulze (2003), utilizing Mg\# and Ca\#, was designed to separate garnets of crustal and mantle origin. Our new dataset reveals, however, that some $66 \%$ of cratonic garnet-granulites misclassify as mantle-derived in this classification scheme. This is problematic for locations where garnet-granulite-derived and other low-Cr crustal garnets are abundant. Hardman et al. (submitted) present new garnet major element-based graphical and statistical schemes and evaluate the usefulness of logistic regression and linear discriminant analysis in detail. They demonstrate how these methods may be applied to exploration datasets from different environments to yield the lowest classification error rate. These new major-element-based methods involve the minor elements Na and/or $\mathrm{Ti}$, thereby placing more stringent requirements on the quality of garnet analyses (i.e., increased accuracy in classification comes at an analytical cost). While error rates can be substantially reduced in these new schemes, some garnets remain indistinguishable, a result in keeping with the findings of Krippner et al. (2014).

The behaviour and exchange of trace elements in garnet (including REE) may differ from that of the major elements. For instance, a temperature and pressure dependency for REE and Y exchange between garnet and omphacite has been proposed (Sun and Liang 2015). As such, trace elements may add an additional dimension to constraining the origin or source lithology of garnets. To-date, no substantial studies have been carried-out into crust versus mantle discrimination using trace elements in garnet. This study aims to evaluate the potential of trace elements, in concert with major elements, to enhance garnet source rock discrimination. 


\section{Results and Discussion}

Median chondrite-normalized $(\mathrm{N})$ REE patterns ( \pm one median absolute deviation) for crust and mantle garnets (Figure 1) are parallel for the $\mathrm{MREE}_{\mathrm{N}}-\mathrm{HREE}_{\mathrm{N}}$ (Sm to Lu), with crustal garnets having up to $>5 \mathrm{x}$ higher concentrations. The median pattern for crustal garnets also is much steeper in the $\mathrm{LREE}_{\mathrm{N}}$ (La to Nd; Figure 1), with slightly lower median concentrations of La and Ce compared to mantle garnets. The shallower $\mathrm{LREE}_{\mathrm{N}}$ slope of mantle garnets likely reflects mantle metasomatism and is a potential first-order discriminant of mantle versus crustal origin. The lower $\mathrm{La}$ and $\mathrm{Ce}$ abundances in crustal garnets may be a response to the frequent occurrence of LREE-enriched accessory phases in crustal rocks.

A much decreased resolving power becomes apparent upon inspection of the full suite of individual REE $_{\mathrm{N}}$ patterns. A bivariate plot comparing LREE $\mathrm{N}_{\mathrm{N}}$ slope $\left(\mathrm{Sm}_{\mathrm{N}} / \mathrm{Ce}_{\mathrm{N}}\right)$ and HREE abundance $\left(\mathrm{Yb}_{\mathrm{N}}\right)$ for the full suite of garnets reveals a significant population overlap (Figure 2).

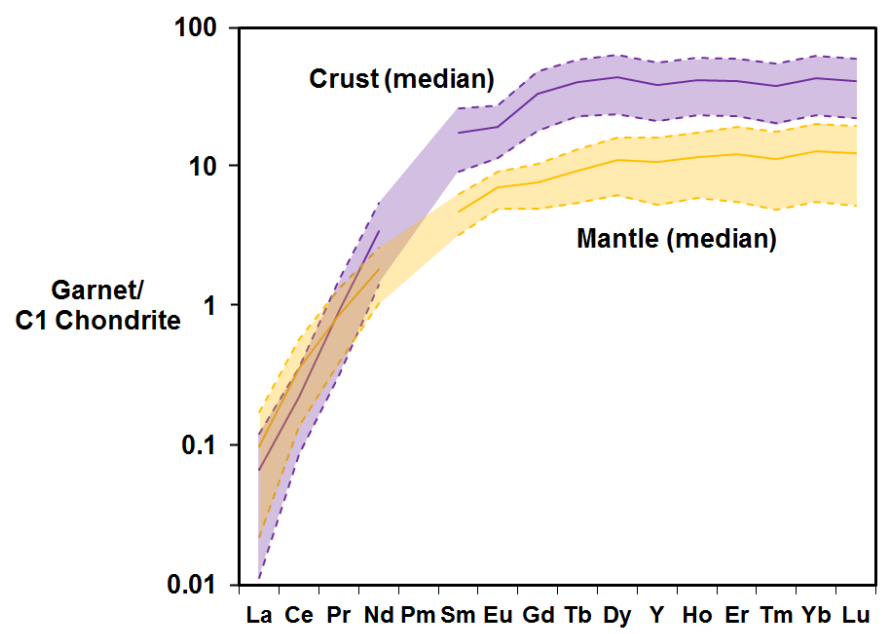

Figure 1: C1 chondrite (McDonough and Sun 1995) normalized REE abundances in low-Cr garnets. Solid lines indicate median concentrations for crust (purple) and mantle (yellow) garnets. Envelopes correspond to one median absolute deviation (MAD). Pm was not analyzed. Y is included with the MREE based on its matching ionic radius and charge.

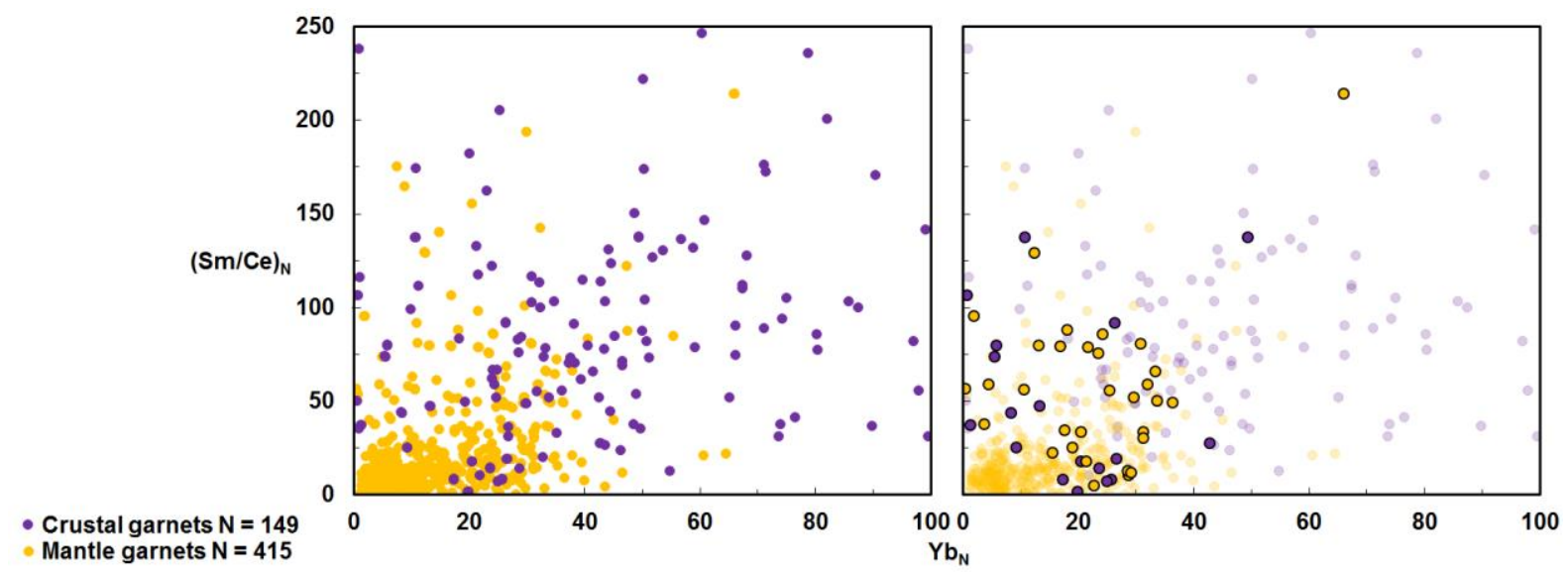

Figure 2: Bivariate plot of $\mathrm{Sm}_{N} / \mathrm{Ce}_{\mathrm{N}}$ versus $\mathrm{Yb}_{\mathrm{N}}$, representing $\mathrm{LREE}_{\mathrm{N}}$ slope and $\mathrm{HREE}_{\mathrm{N}}$ abundance. To better investigate problematic samples, the more solid-coloured yellow and purple points in the rightmost plot are those which misclassify using the Hardman et al. (submitted) graphical method.

To more closely investigate the nature of samples that misclassify using major elements schemes, the compiled trace element dataset $(\mathrm{N}=564)$ is tested against the Schulze (2003) Ca\# versus Mg\# method and the Hardman et al. (submitted) $\ln \frac{M g}{F e * S i}$ versus $\ln \frac{T i}{S i}$ graphical method. The Schulze (2003) method results in a $17.1 \%$ classification error, while the Hardman et al. (submitted) graphical method results 
in only a $9.4 \%$ classification error. Samples that misclassify using the Hardman et al. (submitted) graphical method are highlighted in the rightmost plot in Figure 2. It is observed that in almost all cases their $\mathrm{LREE}_{\mathrm{N}}$ slopes and $\mathrm{HREE}_{\mathrm{N}}$ abundances are transitional between crustal and mantle garnets (i.e. employing REE cannot significantly improve the resolving power of major element based classification schemes).

Other trace element discriminators being explored are $\mathrm{Zr}$ and $\mathrm{Y}$, which both appear to be systematically more enriched in crustal versus mantle garnets. Discriminants using these elements combined with REE ratios will be explored using linear discriminant analysis and logistic regression techniques.

\section{Conclusions}

It is clear that any low-Cr garnet classification schemes must be trained and tested with databases containing cratonic garnet-granulite compositions, which provide the toughest discrimination challenge. As a result of expanding training datasets to include such garnets, the multivariate majorelement statistics-based classification schemes proposed by Hardman et al. (submitted) are the most robust schemes to date. Here we attempted to improve the discrimination power of these approaches by adding trace elements to the mix of elements. While clear differences exist in the median $R E_{N}$ patterns of crust and mantle garnets (different slopes in $\mathrm{LREE}_{\mathrm{N}}$ and distinctly different $\mathrm{HREE}_{\mathrm{N}}$ abundances), examination of the full sample suite shows that discrimination of many garnets is not possible using REE alone. Samples which misclassify using advanced major element based techniques typically also have $\mathrm{REE}_{\mathrm{N}}$ patterns that are inconsistent with the median pattern ( $\underline{\underline{ \pm}}$ one median absolute deviation) of their population (crust or mantle). We are currently evaluating other trace elements (including $\mathrm{Zr}$ ) for their potential to enhance the resolving power of REE-based classifications. However, based on our preliminary results for REE, the usefulness of trace elements as a discriminatory tool likely does not justify the increased time and cost associated with their analysis. Major element-based multivariate approaches, such as linear disciminant analysis and/or logistic regression, using robust data normalization procedures appear to be the most efficient and successful way forward in mantle versus crust garnet classification.

\section{References}

Hardman MF, Pearson DG, Stachel T, Sweeney RJ. Statistical approaches to the discrimination of crustand mantle-derived low-Cr garnet - major-element-based methods and their application in diamond exploration. Submitted to Journal of Geochemical Exploration

Krippner A, Meinhold G, Morton AC, von Eynatten H (2014) Evaluation of garnet discrimination diagrams using geochemical data of garnets derived from various host rocks. Sedimentary Geology 306: $36-52$

McDonough WF, Sun S-s (1995) The composition of the Earth. Chemical Geology 120: 223-253

Schulze DJ (2003) A classification scheme for mantle-derived garnets in kimberlite: a tool for investigating the mantle and exploring for diamonds. Lithos 71: 195-213

Sun C, Liang Y (2015) A REE-in-garnet-clinopyroxene thermobarometer for eclogites, granulites and garnet peridotites. Chemical Geology 393-394: 79-92 